\title{
Выборная К.В. \\ Распространенность соматотипов в популяции и ее связь с физической активностью
} ФГБУН «ФИЦ питания и биотехнологии» (Россия, Москва)

doi: 10.18411/trnio-10-2021-104

\section{Аннотация}

В статье представлен анализ данных литературы и собственных исследований. Цель анализа - охарактеризовать «движение» по соматотипологическому треугольнику ХитКартера соматотипологического облака при занятиях некоторыми видами спорта на профессиональном уровне для обнаружения влияния вида спорта или группы спорта на соотношение компонентов соматотипа. Показано, что соматотипологическое облако спортсменок, занимающихся маскулинными видами спорта, находится на соматотипологическом треугольнике левее оси мезоморфии, чем соматотипологическое облако спортсменок, занимающихся феминными видами спорта, что связано со значительным развитием компонента MESO и меньшим развитием компонента ЕСТО у маскулинных женщин. Также было показано, что боксеры тяжелых весовых категорий более рассредоточены по соматотреугольнику, что говорит о значительной вариабельности компонентов соматотипа в соматотипологической формуле у тяжеловесов; соматотип девушек, занимающихся триатлоном, претерпевает наибольшие изменения, чем соматотип юношей-триатлетов; соматотипологическое облако хоккеисток, принадлежащих к маскулинным видам спорта, смещено на соматотипологическом треугольнике и находится между осями мезоморфии и эндоморфии.

Ключевые слова: физическая активность, спорт, соматотип, схема Хит-Картера, феминные виды спорта, маскулинные виды спорта, бокс, триатлон, женский хоккей с шайбой.

\section{Abstract}

The article presents an analysis of literature data and data from our own research. Purpose to characterize the "movement" along the Heath-Carter somatotypological triangle of the somatotypological cloud when practicing some sports at a professional level to detect the influence of a sport or a group of sports on the ratio of somatotype components. It was shown that the somatotypological cloud of female athletes engaged in masculine sports is located on the somatotypological triangle to the left than the somatotypological cloud of female athletes engaged in feminine sports, which is associated with a significant development of the MESO component and a lower development of the ECTO component in masculine women. It was also shown that boxers of heavy weight categories are more dispersed along the somatotriangle, which indicates a significant variability of somatotype components in the somatotypological formula among heavyweights; the somatotype of girls going in for triathlon undergoes the greatest changes than the somatotype of young men-triathletes; somatotypological cloud of hockey players belonging to masculine sports is displaced on the somatotypological triangle between the mesomorphic and endomorphic axes.

Keywords: physical activity, sport, somatotype, Heath-Carter scheme, feminine sports, masculine sports, boxing, triathlon, women's ice hockey.

Введение. Динамика соматотипа в спортивной практике - это закономерная изменчивость балльных значений компонентов соматотипа и их соотношения в зависимости от вида спорта, пола, целей тренировки, возраста и весовой категории. Баллы компонентов соматотипа отражают развитие жирового (ENDO), мышечного (ESO) и костного (ECTO) компонентов тела и претерпевают изменения в течение всей тренировочной и соревновательной жизни спортсменов. Было показано [2], что соматотип является лабильной морфологической единицей, претерпевающей изменения в зависимости от возраста, весовой категории и игрового амплуа. 
Материалы и методы. Были проанализированы данные литературы $[3,4]$ и данные

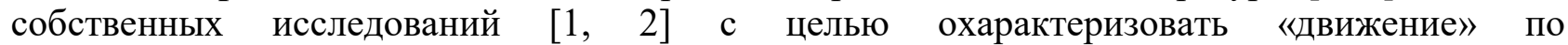
соматотипологическому треугольнику Хит-Картера соматотипологического облака при занятиях некоторыми видами спорта на профессиональном уровне для обнаружения влияния занятия конкретным видом спорта (или группы спорта) на соотношение компонентов соматотипа.

Результаты исследования. При оценке соматотипа с использованием схемы ХитКартера у 618 представителей юношеского возраста - студентов первого курса Познанского университета физического воспитания (Польша) [4] (юноши: $\mathrm{n}=354$, средний возраст 19,5 \pm 1,2 года, ДТ - 180,64 $\pm 5,95$ см, МТ 75,95 \pm 9,83 кг, ИМТ - 23,26 $\pm 2,50$ кг $/ \mathrm{m}^{2}$, ЖМТ\% - 14,36 \pm 4,64 \%, ММТ\% - 61,91 $\pm 6,54 \%$; девушки: $\mathrm{n}=264$, средний возраст 19,2 $\pm 1,2$ года, ДТ $165,92 \pm 6,27 \mathrm{cм}$, МТ 60,53 $\pm 8,74$ кг, ИМТ - 21,93 $\pm 2,70$ кг $/ \mathrm{m}^{2}$, ЖМТ\% - 24,58 $\pm 5,88 \%$, МMT\% -43,16 $\pm 4,80 \%$ было показано (рис. 1a), что групповой соматотип юношей выражался формулой 3,2-3,5-2,9, а девушек - 4,3-2,9-2,7. При разделении всех обследуемых на три группы по преобладанию одного компонента (эндоморф, мезоморф или эктоморф) было показано (рис. 1б), что 45,8\% обследуемых (283 чел) независимо от пола были представителями соматотипа с преобладанием эндоморфного компонента, 27,3 \% (169 чел) мезоморфного компонента и 26,9\% (166 чел) - эктоморфного компонента. Группа эндоморфов включала 28,9 \% юношей (100 чел) и 69,3\% девушек (183 чел), группа мезоморфов - 41,2\% юношей (146 чел) и 8,7\% девушек (23 чел), а группа эктоморфов $29,9 \%$ юношей (108 чел) и 22\% девушек (58 чел) (рис 1в). Юноши являлись в основном (41,2\%) носителями мезоморфного, а девушки (69,3 \%) - эндоморфного соматотипа.

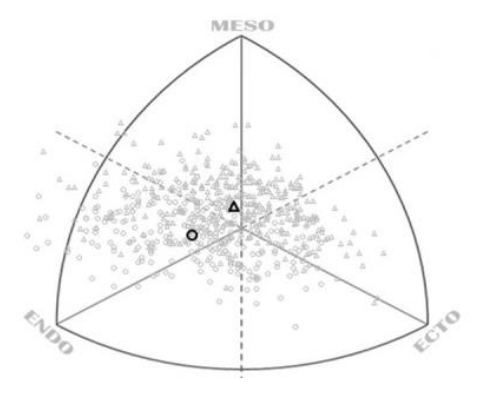

$\Delta \quad-\quad Ю н, n-354$
○ - Дев, $n-264$

$1 a$

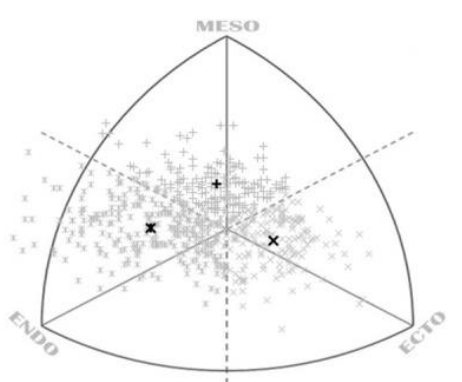

$\mathbf{x} \quad-\quad$ Endo, $n-283$
$\mathbf{+}-$ Meso, $n-169$
$\mathbf{\times} \quad$ Ecto, $n-166$

16

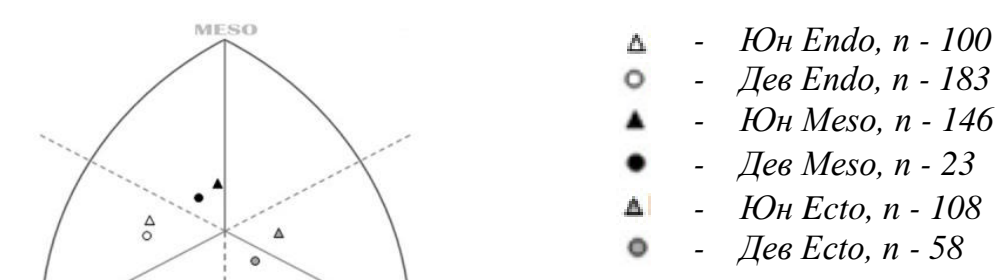

16

Рисунок 1. Распределение обследованных студентов [4] на соматосрезе Хит-Картера с выделением среднего соматотипа:

$1 a-$ для юношей (Юн) и девушек (Дев);

16 - для эндоморфов( Endo), мезоморфов (Mеso) и эктоморфов (Ecto) без разделения по полу; 18 - для групп в соответствии с полом и компонентами соматотипа 
Результаты данного исследования [4] наглядно демонстрируют, что в популяции условно здоровых людей молодого возраста присутствуют представители всех соматотипов, а соматотипологическое облако имеет форму овала, вытянутого более всего к оси ENDO и менее всего - к оси MESO (рис. 2a). При разделении юношей и девушек на два отдельных кластера видно, что соматотипологическое облако юношей более смещено к оси мезоморфии вверх по соматотреугольнику, а облако девушек тяготеет к оси эндоморфии и смещено вниз по соматотреугольнику (рис. 2б).

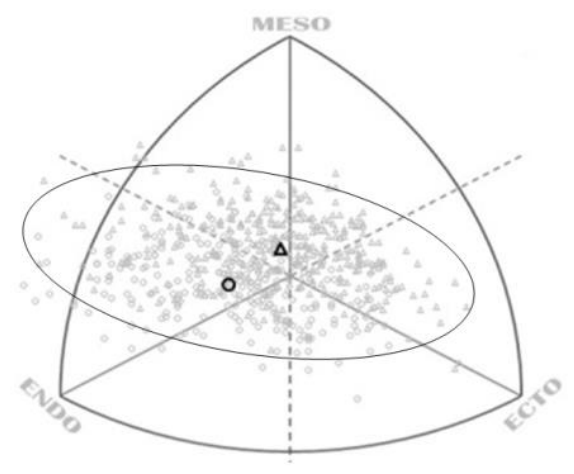

$2 \mathrm{a}$

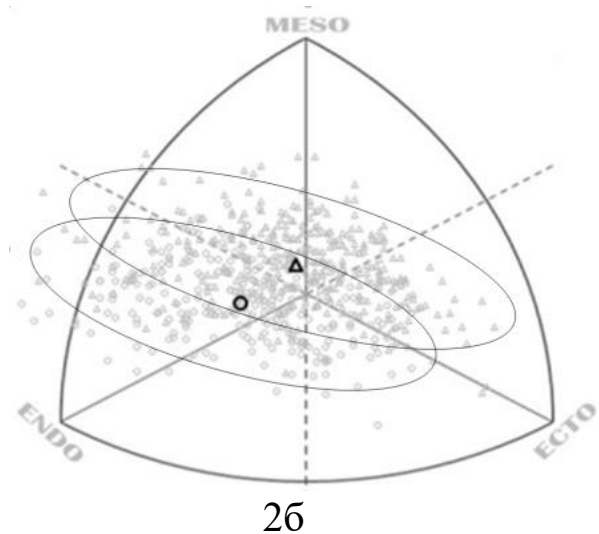

Рисунок 2. Обозначение грании соматотипологического облака на соматосрезе Хит-Картера [4] для: $2 a$ - всех обследованных студентов;

$2 б$ - для группь юношей и группь девушек отдельно

При этом соматотипологические облака в группах спортсменов имеют тенденцию к изменению положения на соматосрезе.

Так, при обследовании спортсменок, занимающихся маскулинными (рис. 3a) и феминными (рис. 3б) видами спорта показано, что особенностью женщин, занимающихся борьбой $(\mathrm{n}=29 ; 3,8-4,9-2,3)$, боксом $(\mathrm{n}=31 ; 3,2-4,8-2,8)$ и фехтованием $(\mathrm{n}=30 ; 3,0-5,0-2,9)$ является значительное развитие компонента MESO и меньшее развитие компонента ЕСTO по сравнению с женщинами, занимающимися художественной гимнастикой $(\mathrm{n}=31 ; 2,5-3,5$ $4,2)$, спортивной аэробикой $(\mathrm{n}=30 ; 3,2-4,8-3,6)$ и фигурным катанием $(\mathrm{n}=29 ; 3,4-4,1-3,7)$ [3]. Именно поэтому соматотипологическое облако маскулинных спортсменок находится на соматотипологическом треугольнике левее оси мезоморфии (рис. 3a), чем соматотипологическое облако феминных спортсменок (рис. 3б).

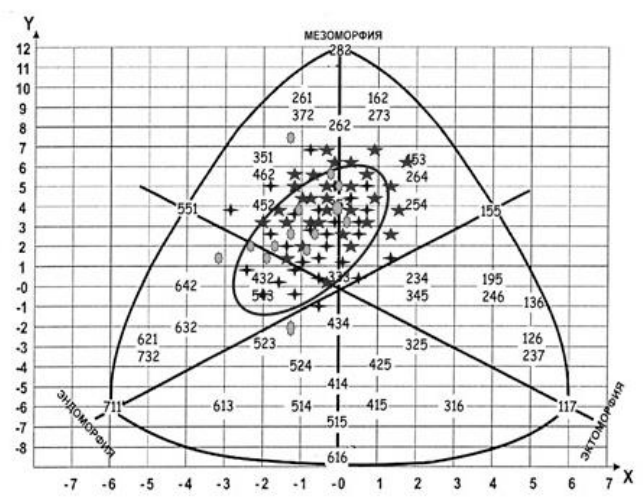

$3 a$

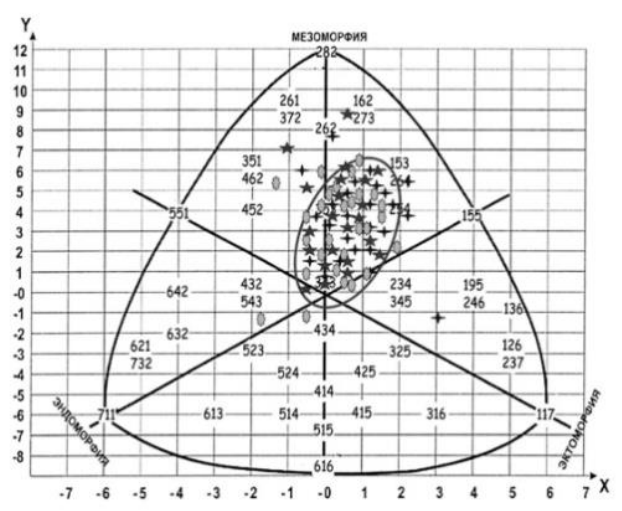

36

Рисунок 3. Соматотип, характерный для представительнии маскулинных (3а: борьба, бокс и фехтование) и феминных (3б: художественная гимнастика, спортивная аэробика и фигурное катание) видов спорта [3]

При обследовании высококвалифицированных боксеров - членов молодежной сборной команды РФ по боксу $(\mathrm{n}=34)$ было показано [1], что групповой соматотип боксеров 
(без разделения на весовые категории) отличается от группового соматотипа представителей группы контроля в сторону увеличения компонентов ENDO и MESO и уменьшения компонента ЕСТО. Представители бокса обладают преимущественно эндомезоморфным соматотипом $(2,8-5,5-2,4)$ с превалированием мышечного и жирового компонентов (рис. 4a).
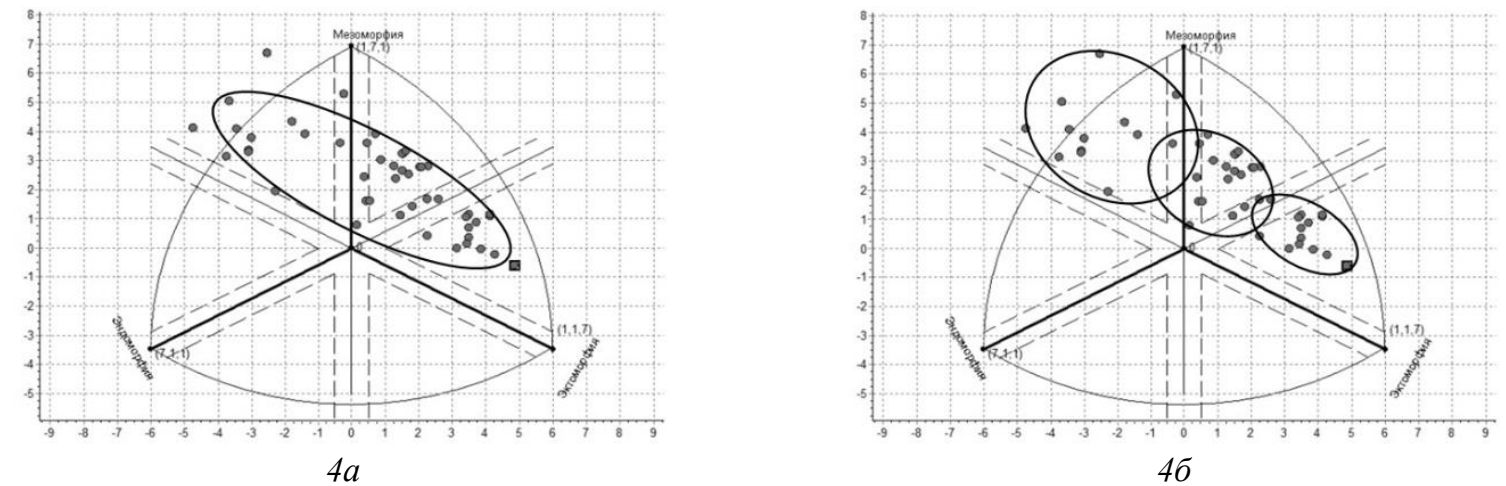

Рисунок 4. Соматотип боксеров слитно (4a) и при разделении на 3 весовые категории (4б)

При разделении тех же боксеров на группы согласно весовым категориям было показано, что соматотипологическая характеристика боксеров меняется: с увеличением весовой категории наблюдается выраженная динамика соматотипа от эктомезоморфного 2,35,1-3,2 (с преобладанием мышечного и костного компонентов) к эндомезоморфному 4,0-6,11,1 (с преобладанием мышечного и жирового компонентов). При этом превалирование мышечного (мезоморфного) компонента, указывающего на хорошее развитие мышечной массы тела, было обнаружено у спортсменов во всех весовых категориях. Жировой эндоморфный компонент является превалирующим в тяжелых весовых категориях, а костный эктоморфный компонент является превалирующим в легких весовых категориях.

На рисунке 46 представлено разделение соматотипологического облака обследованных боксеров на части согласно разделению на три условные весовые категории: легкие, средние и тяжелые. Характерным является то, что спортсмены тяжелых весовых категорий более рассредоточены по соматотреугольнику, что говорит о значительной вариабельности компонентов соматотипа в соматотипологической формуле у данной группы боксеров.

При обследовании триатлетов (рис. 5) (юноши и мужчины, $\mathrm{n}=20$, средний возраст $17,8 \pm 2,2$ лет (15,2-22,6 лет); девушки и женщины - n=15, средний возраст - $16,6 \pm 2$ лет $(14,2-$ 21,3 лет) - членов олимпийской молодежной и взрослой сборных команд России по триатлону, показано, что триатлеты обоих полов отличаются от представителей группы контроля увеличением компонента ЕСТО и уменьшением компонентов ENDO и MESO в соматотипологической формуле. Юноши-триатлеты и представители группы контроля обладают экто-мезоморфным групповым соматотипом, с превалированием мышечного и костного компонентов; соматотипологический профиль триатлетов представлен формулой 2,1-4,3-3,8, а представителей контрольной группы - 2,4-4,9-3,2. Групповой соматотип девушек-триатлеток выражен формулой 3,2-3,9-3,4, что говорит о наличии эктомезоморфного соматотипа с превалированием мышечного и костного компонентов, тогда как соматотип девушек группы контроля - эндо-мезоморфный (3,9-4,5-2,7), с превалированием мышечного и жирового компонентов соматотипа.

Соматотипологические облака триатлетов, как мужчин (рис. 5а), так и женщин (рис. 56), локализованы и более ограничены, чем облака представителей контрольной группы и не имеют «выскакивающих» соматотипов с избыточно развитым жировым компонентом. Соматотип девушек, занимающихся триатлоном, претерпевает наибольшие изменения, чем соматотип юношей-триатлетов. 

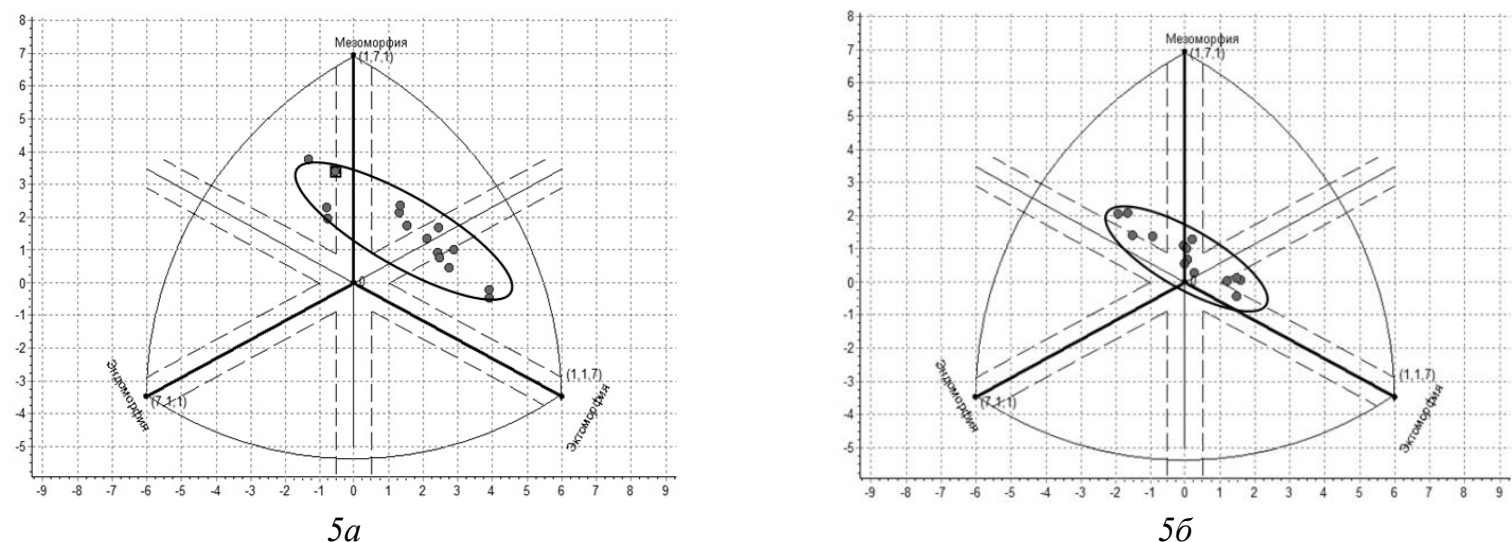

Рисунок 5. Соматотип триатлетов - мужчин (5a) и триатлетов - женщин (5б)

При обследовании женщин - игроков женской сборной команды России по хоккею с шайбой $(n=25$, средний возраст $22,4 \pm 3,6$ лет) [2] показано, что групповой соматотип хоккеисток эндомезоморфный (рис. 6) и выражен формулой 4,2-5,0-2,0.

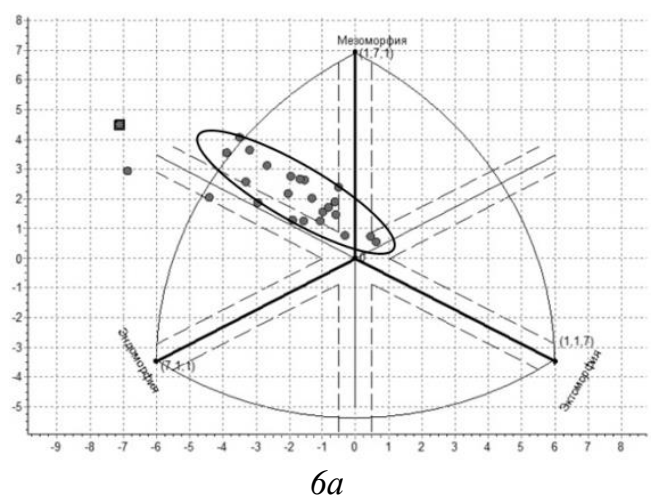

Рисунок 6. Соматотип хоккеисток

При разделении спортсменок на группы согласно игровым амплуа показано, что нападающие имеют достоверно меньший балл эндоморфии ( $\mathrm{n}=13 ; 3,9-5,0-2,2)$, чем защитники $(\mathrm{n}=9 ; 4,4-5,2-1,7)$ и вратари $(\mathrm{n}=3 ; 4,5-4,7-2,4)$, что говорит о том, что у нападающих менее всего развит жировой компонент по сравнению с представительницами других амплуа. Соматотипологическое облако хоккеисток, принадлежащих к маскулинным видам спорта, смещено на соматотипологическом треугольнике между осями мезоморфии и эндоморфии.

Заключение. Несмотря на разнонаправленное влияние видов спорта на формирование соматотипа спортсменов, соматотипологические облака женщин, за счет меньшего, чем у мужчин, мышечного компонента массы тела, а также большего жирового компонента, больше тяготеют к оси эндоморфии, а соматотипологические облака мужчин «смещены» вверх по оси мезоморфии. При этом, в зависимости от группы спорта, облака могут смещаться либо к эндоморфии (например, у представителей силовых и игровых видов спорта), либо к эктоморфии (например, у представителей сложно-координационных и циклических видов спорта).

1. Выборная К.В., Семенов М.М., Лавриненко С.В., Раджабкадиев Р.М. Соматотипологическая характеристика высококвалифицированных боксеров // Боевые искусства и спортивные единоборства: наука, практика, воспитание: Материалы V Всероссийской научно-практической конференции с международным участием (статья) (Москва, 15 октября 2020 г.) / Под общ. ред. Ю.Л. Орлова, Л.Г. Рыжковой. - М.: Лика, 2020. - 300 с. ISBN 978-5-6043178-1-5, C. 99-105.

2. Выборная К.В., Семенов М.М., Лавриненко С.В., Раджабкадиев Р.М., Никитюк Д.Б. Динамика компонентов соматотипа спортсменов в зависимости от возраста и спортивной специализации // Материалы IV 
Всероссийской научно-практической конференции с международным участием по спортивной науке: «Подготовка спортивного резерва» 1-2 декабря 2020г. (статья) ГКУ «ЦСТиСК» Москомспорта, ФЦПСР Минспорта, в формате PDF - М.: ГКУ «ЦСТиСК» Москомспорта, 2020. - 569 страниц. ISBN 978-5-99052529-0, c. 84-87.

3. Ткачук М.Г., Дюсенова А.А. Морфологические признаки полового диморфизма у женщин-спортсменок: монография: НГУ им. П.Ф.Лесгафта. СПБ, 2009.- 112 с.

4. Krzykała Magdalena, Karpowicz Małgorzata, Strzelczyk Ryszard, Pluta Beata, Podciechowska Karolina, Investigation, Karpowicz Krzysztof; Loenneke, Jeremy P. (2020). Morphological asymmetry, sex and dominant somatotype among Polish youth. PLOS ONE, 15(9), e0238706-. doi:10.1371/journal.pone.0238706

\section{Елькина Н.А., Осипова А.А. \\ Адаптированность генеративной сферы Tripolium pannonicum (астры солончаковой) к условиям обитания на приливно-отливной зоне побережья Белого моря}

Петрозаводский государственный университет (Россия, Петрозаводск)

doi: 10.18411/trnio-10-2021-105

\section{Аннотация}

Астра солончаковая - типичный галофит, обитающий на приливно-отливной зоне побережья Белого моря. Нами исследованы морфологические характеристики пыльцы астры солончаковой, проведена оценка количества нормально сформированной пыльцы и различных форм тератов, изучена адаптированность астры к генеративному размножению на разных зонах литорали.

Ключевые слова: пыльцевое зерно, адаптивный потенциал, тератоморфы, Белое море.

\section{Abstract}

Sea aster is a typical halophyte of the intertidal zone of the White Sea coast. We measured the morphological characteristics of the pollen of the sea aster, assessed the amount of normally formed pollen and various forms of terata. Adaptation of the aster to generative reproduction in different zones of the littoral was studied.

Keywords: pollen grain, adaptive potential, teratomorphs, White Sea.

Большие экономические перспективы развития Арктического региона диктуют необходимость проведения исследований биоты для оценки уязвимости экосистем и их компонентов и возможных реакций на различные воздействия. Организмы (в том числе растения), обитающие на литорали, в разной степени адаптированы к обитанию в постоянно изменяющихся условиях приливно-отливной зоны. Часть Северного Ледовитого океана Белое море - удобный для проведения мониторинговых исследований водоем. На береговой зоне, в месте контактов различных сред (водная, воздушная, почвенная) наиболее активно происходят процессы видообразования и отмечается большая продуктивная активность. Таким образом, по состоянию небольшой модельной территории можно оценивать благополучие бо́льших частей моря или океана.

Особенности биологии типичного представителя прибрежной зоны Белого моря Астры солончаковой Tripolium pannonicum (Jacg.) Dobrocz. Subsp. tripolium (L.) Greuter для оценки состояния ценопопуляций на различных субстратах по градиенту суточной динамики заливания исследованы в ряде работ $[3,6,7]$. Однако эколого-биологические свойства вида, позволяющие успешно реализовывать жизненный цикл и взаимодействовать с факторами абиотической среды в настоящее время изучены недостаточно. 